\title{
Regulatory $T$ cells exhibit neuroprotective effect in a mouse model of traumatic brain injury
}

\author{
YUNHU YU ${ }^{1}$, FANG CAO ${ }^{2}$, QISHAN RAN ${ }^{3}$ and XIAOCHUAN SUN ${ }^{1}$ \\ ${ }^{1}$ Department of Neurosurgery, The First Affiliated Hospital of Chongqing Medical University, Chongqing 400016; \\ ${ }^{2}$ Department of Cerebrovascular Disease, The First Affiliated Hospital of Zunyi Medical College; ${ }^{3}$ Department of \\ Neurosurgery, The Third Affiliated Hospital of Zunyi Medical College, Zunyi, Guizhou 563000, P.R. China
}

Received August 18, 2016; Accepted November 14, 2016

DOI: $10.3892 / \mathrm{mmr} .2016 .5954$

\begin{abstract}
Traumatic brain injury (TBI) is a major health and socioeconomic problem as it is associated with high rates of mortality and morbidity worldwide. Regulatory $\mathrm{T}$ cells (Tregs) have been reported to reduce inflammatory response in several diseases, including myasthenia gravis, viral myocarditis and cerebral infarction. The present study investigated the role of Tregs in mediating neuro-protective effects in a mouse model of TBI. Initially, Treg levels were determined, and compared between the controlled cortical impact (CCI) model for moderate TBI and the sham group, by using flow cytometry and ELISA. Afterwards, the number of Tregs was upregulated (by injection) and downregulated (by depletion), respectively, to elucidate the effect of Tregs in the presence of an inflammatory reaction and a deficient neurological function and consequently, in the prognosis of TBI in the mouse. The expression of pro-inflammatory cytokines [tumor necrosis factor (TNF)- $\alpha$, interleukin (LL)-1 $\beta, \mathrm{IL}-6)$ and anti-inflammatory cytokines [1L-10, transforming growtly factor (TGF)- $\beta$ ] in blood and brain tissues was also measured in the five groups: Mice receiving a saline injection, mice experiencing Treg depletion, small-dose (SD Tregs, $1.25 \times 10^{5}$ ), and mice receiving different doses of Tregs: Moderate-dose

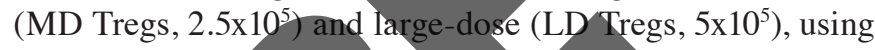
ELISA and PCR. Co-cultures of Tregs and microglia were performed to evaluate the expression of pro-inflammatory cytokines and observe the interaction between the two types of cells. The regulation patterns in JNK-NF-KB pathway by Tregs were also evaluated by western blot analysis. Treg levels were significantly reduced in TBI mouse group on the 3rd day
\end{abstract}

Correspondence to: Dr Xiaochuan Sun, Department of Neurosurgery, The First Affiliated Hospital of Chongqing Medical University, 1 Youyi Road, Chongqing 400016, P.R. China E-mail: sunxiaochuan0709@163.com

Key words: cytokines, FoxP3, inflammatory response, microglia activation, neuro-protective effect, regulatory $\mathrm{T}$ cells, traumatic brain injury after TBI $(\mathrm{P}<0.05)$. In the mouse model of TBI, the expression of pro-inflammatory cytokines (TNF- $\alpha$, IL-1 $\beta$, IL-6) was enhanced, while the expression of anti-inflammatory cytokines (IL-10, TGF- $\beta$ ) was reduced $(\mathrm{P}<0.05)$. Tregs exhibited a suppressive effect on inflammatory reactions. In the MD group, the activation of microglia cells was markedly inhibited, compared to the activation in SD and LD groups. The expression of ERK1/2, JNK1/2/3 and NK- $\mathrm{KB}$ was significantly downregulated in the MD group. The results indicated that Tregs exhibited significant neuro-protective effects, suppressing pro-inflammatory responses and promoting tissue repair after TBI injury in the mouse, specifically by deactivating the JNK-NF- $\mathrm{kB}$ pathway. The results of the study show that Tregs potentially participates in neuro-therapeutic approaches for TBI.

\section{Introduction}

Traumatic brain injury (TBI) is normally caused by an external mechanical force that traumatically injures the brain. It can be classified based on severity, nature of the impact or other features (1-3). Currently, TBI is one of the major causes of death and disability worldwide, especially in children and young adults. The number of young cases that suffer from brain injuries has been drastically increasing over the years $(1,2)$.

Although the number of drugs that are capable of ameliorating cerebral injuries remain scarce, a significant progress has been made in understanding the pathological mechanism of TBI and in developing a possible treatment. It is known that following the occurrence of TBI, other events such as inflammatory reactions, oxidative stress responses, and cytotoxicity injuries develop, and together they elicit a secondary craniocerebral injury, mainly driven by the inflammatory component $(4,5)$. The inflammatory reaction in the brain usually involves the necrosis or death of numerous neurons as well as the activation of microglial cells (6-8). Peripheral blood lymphocytes, neutrophil granulocytes and thrombin invade the central nervous system (CNS), passing through the injured blood-brain barrier (9-12). Consequently, the expression of many cytokines is up- or downregulated at the same time that resident microglia cells are activated. Previous studies suggested that TBI, of either moderate or severe levels, 
induces chronic microglial activation that may negatively affect prognosis. It was also suggested that the activation of these cells may be the result of delayed cell death and tissue loss (5). Overall, all these changes in the immune system further exacerbate the apoptosis and necrosis of neurons, aggravating the injury and further impairing the neurological function (13-15).

On the other hand, recent studies have demonstrated that regulatory $\mathrm{T}$ cells (Tregs) are involved in immunomodulation, alleviating the inflammatory reaction and tissue damage (6-12). CD4 T cells that constitute Tregs are usually associated with CD25 and FoxP3 markers. Sakaguchi et al (13) confirmed that CD25 is a surface phenotypic marker for suppressive CD4 cells in mice. On the other hand, FoxP3 belongs to the forkhead/winged-helix family of transcription factors, acting as the 'master regulator' in the establishment of Tregs as a terminally differentiated and lineage committed subset of CD4 T cells (13).

Tregs can reduce cerebral infarction and improve behavioral function, and are positively associated with neuro-regeneration and alleviation of local inflammation. They have also shown to regulate immunity and inflammation in several diseases, including brain ischemia, viral myocarditis, inflammatory bowel disease, and myasthenia gravis $(16,17)$. However, their underlying pathological and physiological mechanisms continue unknown. In certain studies in atherosclerosis, it was found that Tregs stimulate the secretion of anti-inflammatory cytokines of interleukin (IL)-10 and transforming factor (TGF)- $\beta$ (18-22).

Since few studies have examined the function of Tregs in TBI patients, little is known about the physiological functions of Tregs in this condition. However, clinical trials have corroborated that the upregulation of Tregs in TBI patients significantly improves their clinical condition (12). Therefore more studies are required to confirm their neuro-protective effects in TBI, since a better understanding can remarkably improve diagnosis, treatment and prognosis of the condition, as well as provide theoretical basis for novel treatment of TBI.

By analyzing the expression of Tregs and corresponding cytokines in the peripheral and CNSs, the present study aimed to elucidate the association between the changes of the immune system and in presence of TBI, by upregulating and downregulating the Tregs concentration in a mouse model of TBI.

Co-cultures of Tregs and microglia cells were performed to determine the immunological effect of Tregs. Our data showed that Tregs considerably suppressed microglia activation, while in the group of Treg depletion, microglia activation exhibited the highest level.

Moreover, JNK and p38 MAPK signaling pathways have been reported as critical factors during neuro-inflammation. In the current study, the expression patterns of JNK1/2/3, p38 MAPK, ERK1/2 and NF- $\kappa$ B proteins were identified among all the studied groups. However, our findings suggested that in the group with exogenous Treg injection, the expression levels of JNK1/2/3, p38 MAPK, ERK1/2 and NF- $\kappa$ B proteins were significantly reduced, compared to their levels in other groups. The data indicated that Tregs attenuate the inflammatory response by suppressing the JNK and NF- $\kappa \mathrm{B}$ signaling pathways.

\section{Materials and methods}

Animals. C57BL/6 mice, 6-8 weeks of age, were used in the current study. Animals were randomly separated into two groups, sham and TBI group. In both groups, food and tap water were provided without restriction and the housing temperature was strictly controlled. All the animal protocols were approved by the Committee of Ethics and performed at Animal Experiments of the Experimental Animal Research Institute. Every effort was made to minimize animal suffering.

Mouse controlled cortical impact (CCI) model of moderate TBI. The CCI model was used to induce traumatic brain injuries in mice. TBI group consisted of 8 mice, which were anesthetized via IP injection of a Ketamine/xylazine mixture $(87.7 \mathrm{mg} / \mathrm{ml}$ Ketamine and $12.3 \mathrm{mg} / \mathrm{ml}$ Xylazine) $(1 \mathrm{ml} / \mathrm{kg})$. The heads of mice were shayed between the ears and sterilized with $10 \%$ jodine, followed by $70 \%$ ethanol. Subsequently, a midline incision was performed to expose the skull, and the anatomical landmarks Lambda (caudal aspect) and Bregma (frontal aspect) were identified, by drawing a circle in the center with a $4 \mathrm{~mm}$ diameter and $0.5 \mathrm{~mm}$ away from the midline. The marked circle was cut along and the bone dust was gently blown away, in case the dura mater was damaged. Afterwards, the injury was achieved by introducing the impactor tip into the brain with a $1.0-\mathrm{mm}$ depth of impact. The diameter of the impactor tip was $3 \mathrm{~mm}$. Parameters to produce moderate TBI were set as follows: the velocity of the actuator was $3 \mathrm{~m} / \mathrm{sec}$, and impact duration was $100 \mathrm{msec}$. After injury, the area was carefully leaned from any residual blood with a cotton-tipped appliator. Once bleeding stopped, the wound was sutured. The mice then returned a the clean cage and recovered from the surgery. The sham group consisted of 7 mice, which did not receive the injury.

The comparison of Treg levels between TBI group and Sham group were conducted at days 1, 3 and 7 post-injury. Brain tissues were harvested, fixed and embedded with paraffin for further examination of the number of Treg cells present at these time points. Formalin-fixed hematoxylin-eosin stained sections were also examined by a pathologist, who was blinded to the status of the mice, by light microscopy.

Splenocyte isolation. All the steps were performed under a sterile laminar flow hood to assure sterility of the procedure. Animals were euthanized by cervical dislocation. After sterilization of the abdomen area with $70 \%$ ethanol, a first transversal cut, without opening the peritoneal cavity, was performed. The peritoneal sac was identified and excised in order to collect the spleen. The spleen was cleared from residual debris and fat tissue, by washing it twice with $1 \mathrm{X}$ phosphate-buffered saline (PBS). Subsequently, the spleen was cut in two halves, by using microscope glass slides previously sterilized with $70 \%$ ethanol and fire. Spleen contents were removed by squeezing the two halves between the slides to extract the cellular matrix contained within the spleen capsule. The remaining fibrous tissue was discarded and cell aggregates obtained from this procedure were resuspended in complete RPMI-1640 medium. 
Lysis of erythrocytes. Red blood cells were lysed by resuspending the obtained cell pellet in $5 \mathrm{ml}$ of ACK buffer for $90 \mathrm{sec}$. Immediately afterwards, the cell suspension was washed with $45 \mathrm{ml}$ of $1 \mathrm{X}$ PBS to remove any residual of the ACK buffer. Cells were centrifuged at $400 \mathrm{x}$ g for $10 \mathrm{~min}$ and subsequently resuspended in $10 \mathrm{ml}$ of $1 \mathrm{X}$ PBS. Successful lysis of red cells was confirmed by the presence of a white cellular pellet. Number of cells were determined.

Magnetic sorting of Tregs. $\mathrm{CD} 4^{+} \mathrm{CD} 25^{+}$Tregs were isolated from $1 \times 10^{8}$ splenocytes, and according to the manufacturer's guideline (cat. no. 130-091-041; Miltenyi Biotec GmbH, Bergisch Gladbach, Germany). Specifically, splenocytes were labelled with $100 \mu$ l of biotinylated antibody cocktail specific for non-CD4 ${ }^{+} \mathrm{T}$ cells and diluted with $400 \mu \mathrm{l}$ of RPMI-1640 $10 \%$ FBS for $15 \mathrm{~min}$, then $200 \mu \mathrm{l}$ of the antibody specific for biotin and conjugated with microbeads was added and further diluted with $300 \mu \mathrm{l}$ of RPMI-1640 10\% FBS and the mix was incubated for $10 \mathrm{~min}$. After labeling, cells were washed once with RPMI-1640 10\% FBS and re-suspended in $6 \mathrm{ml}$ of RPMI-1640 containing $10 \% \mathrm{FBS}$. Indirect separation of CD4 ${ }^{+}$ cells was obtained by loading $2 \mathrm{ml}$ of the labeled cells onto an LD separation column (Miltenyi Biotec $\mathrm{GmbH}$ ). During this procedure, CD4-negative cells remained in the column, since the magnetic beads were attached to their surfaces, whereas, CD4-positive cells, flew through the column and were finally collected in a new tube. The final number of $\mathrm{CD}^{+}$cells was determined.

The cell population was further enriched in Tregs through a positive selection of $\mathrm{CD} 25^{+}$cell surface marker. Briefly, the obtained cells were labeled with an antibody against CD25-PE and incubated for $15 \mathrm{~min}$. The cells were incubated for another $15 \mathrm{~min}$, but this time in the presence of an anti-PE antibody conjugated with microbeads (Miltenyi Bíotec GmbH). cells were washed once with $10 \mathrm{ml}$ of RPMI $10 \% \mathrm{FBS}$ and then re-suspended in $6 \mathrm{ml}$ of complete medium. CD $4^{+} \mathrm{CD} 25$ cells were separated from $C D 4^{+} \mathrm{CD} 25^{+}$cells by loading the labelled mix into the LS positive selection column (Miltenyi Biotec $\mathrm{GmbH}), 1 \mathrm{ml}$ at a time. Finally, $\mathrm{CD} 4{ }^{+} \mathrm{CD} 25^{+}$cells were collected and quantified.

Flow cytometry analysis. The detection of $\mathrm{CD} 4{ }^{+} \mathrm{CD} 25^{+}$ cells with CD4-FITC and anti-CD25-PE antibodies was performed as follows: $2.5 \times 10^{5} \mathrm{CD}{ }^{+} \mathrm{CD} 25^{+}$cells were resuspended in $100 \mu \mathrm{l}$ of PBS $0.2 \%$ BSA. $1 \mu \mathrm{l}$ of each antibody: CD4-FITC and anti-CD25-PE was added to the sample (1:100 dilution). After 10 min incubation, the cells were washed and analyzed using flow cytometry to determine the obtained cell purity. Generally, an $80 \%$ purity of $\mathrm{CD} 4^{+} \mathrm{CD} 25^{+}$cells can be achieved with this protocol, according to the manufacturer's instructions.

In vitro expansion of Tregs. In the present study, we used mouse Treg expansion kit (cat. no. 130-095-925; Miltenyi Biotec $\mathrm{GmbH}$ ) to conduct in vitro expansion of Treg cells. All procedures were carried out according to the manufacturer's instructions. Treg cells were resuspended at a concentration of $2 \times 10^{6}$ cells $/ \mathrm{ml}$ in complete culture medium containing $2,000 \mathrm{U} / \mathrm{ml} \mathrm{rIL}-2$. Tregs $(50 \mu \mathrm{l})$ were incubated with $50 \mu \mathrm{l}$ of CD3/CD28 MACSiBead Particles in a well of a 96-well flat bottom plate (day 0). At day 1, $100 \mu 1$ media including 2,000 U/ml IL-2 was added, and at day 3, cells were split and then $100 \mu \mathrm{l}$ medium including 2,000 U/ml rIL-2 was added. After 7 days of culture, CD3/CD28 MACSiBead Particles were removed together with the $\mathrm{CD} 3 / \mathrm{CD} 28$ cells bound to them by magnetic cell separation. Treg population was collected for further analysis.

Immunohistochemistry. The paraffin-embedded tissue from each group was cut into $6 \mu \mathrm{m}$ sections and repaired with high voltage. Sections were cooled at RT and then rinsed twice in deionized water and threse times in PBS ( $5 \mathrm{~min} / \mathrm{wash}$ ). The sections were incubated with FOXP3 primary antibody (1:400, ab20034; Abcam, Cambridge, UK) diluted in 2\% BSA at $4^{\circ} \mathrm{C}$ overnight. Not bound FoxP3 antibodies were removed by rinsing the tissue twice with PBS ( $2 \mathrm{~min} / \mathrm{wash})$. Finally, the non-biotinylated goat anti-rabbit IgG secondary antibody was incubated with the primary antibody for $20 \mathrm{~min}$ at room temperature (RT), followed by three rinses with PBS (5 min/wash). The colored reaction product was developed using Simple Stain DAB solution.

Isolation and culture of microglia cells. Procedures were conducted under sterile conditions. The base of a $75 \mathrm{~cm}^{2}$ culture flask was coated with $5 \mathrm{ml}$ poly-D-lysine $(10 \mu \mathrm{g} / \mathrm{ml})$ and allowed to set overnight at RT. Excess of poly-D-lysine was removed and the flask was washed once with PBS. The cleaned culture cabinet was exposed to additional $30 \mathrm{~min}$ of $\mathrm{UV}$ light to maximize the sterilization process. Brains from five fetal BALB/c mice (1-3 days old) were harvested and subjected to disruption by incubating them with $2 \mathrm{ml}$ of rypsin/EDTA $(0.05 / 0.02 \%)$ solution, in the incubator at $37^{\circ} \mathrm{C}$ $10 \mathrm{~min}$ to allow for enzymatic disaggregation. Following neutralization of the trypsin with media, large pieces of tissues were further disaggregated by passing the cell suspension through a $70 \mu \mathrm{m}$ nylon cell strainer. Finally, the suspended cells were added to a poly-D-lysine coated flask and were allowed to grow for 10-14 days, replacing the media every 3 days. Once the cells were $80-90 \%$ confluent, they were transferred to a poly-D-lysine pre-coated 24 -well tissue culture plate $\left(1 \times 10^{5}\right.$ cells/well) and incubated at $37^{\circ} \mathrm{C}$ in a humidified $5 \% \mathrm{CO}_{2}$ atmosphere. Within three days of culture, the obtained cells were assayed for their purity by flow cytometry using the anti-CD11b monoclonal antibody.

Western blotting analysis. Protein extracts from mouse brain tissues were obtained by grinding the tissue into powder in liquid nitrogen with RIPA buffer. The extracted proteins were quantified using BCA assay kit (Thermo Fisher Scientific, Waltham, MA, USA). Subsequently, $40 \mu \mathrm{g}$ of protein extracts were separated by SDS-PAGE, then transferred onto a PVDF membrane (Millipore Corp., Billerica, MA, USA) for detection of specific proteins. The membranes were blocked for 30 min at RT with 5\% non-fat dry milk and incubated for $2 \mathrm{~h}$ with primary antibodies. All the primary antibodies: ERK1/2 (cat. no. ab17942, diluted 1:1,000), JNK1+JNK2+JNK3 antibody (EPR18841-95) (cat. no. ab208035, diluted 1:1,000), JNK1+JNK2+JNK3 (phospho T183+T183+T221) (cat. no. ab124956, diluted 1:1,000), p38 MAPK (cat. no. ab197348, diluted 1:1,000), p38 (phospho Y182) antibody 
(cat. no. ab47363, diluted 1:1,000) were purchased from Abcam. Western blot analysis were conducted by incubating the membrane with the above-mentioned antibodies overnight in a humidified container at $4^{\circ} \mathrm{C}$. Following binding of primary antibodies to the specific proteins in the extract, the membrane was washed with PBST three times and finally incubated with HRP-conjugated secondary antibody for $2 \mathrm{~h}$. The specific proteins were detected and quantified using ECL (Millipore, Corp.) and Quantity One software (Bio-Rad, Berkeley, CA, USA).

RNA extraction and $q P C R$ analysis. Total RNAs from the tissues of TBI and sham groups were isolated from harvested cells and mouse brain tissues with TRIzol (Invitrogen Life Technologies, Carlsbad, CA, USA), according to the manufacturer's instructions. RNAs were reverse transcribed using the PrimeScript $^{\mathrm{TM}}$ RT-PCR kit (Takara Bio, Dalian, China). Real-time PCR reactions were performed using SYBR Premix DimerEraser system (Takara Bio). The PCR primers were designed as follows: IL-10 forward, 5'-ACAACATACTGC TAACCGACTCCT-3' and reverse, 5'-TGCTCCACTGCC TTGCTCTTAT-3'; and TGF- $\beta$ forward, 5'-TGTCGTGGCAGT CCTTCTCAA-3' and reverse, 5'-GCAGGTCAATGTCGG TGTAGC-3'. The PCR primers for tumor necrosis factor (TNF)- $\alpha$ were: forward, 5'-AGCCAGGAGGGAGAACAG AAAC-3' and reverse, 5'-GCCACAAGCAGGAATGAGAA GAG-3'; The PCR primers for IL-1 $\beta$ were: forward, 5'-ATC TCGCAGCAGCACATCAAC-3' and reverse, 5'-TAGAGC GTCGTCGTGTAGTTG-3'; The PCR primers for IL-6 were: forward, 5'-CCACCAAGAACGATAGTCAATTCCA-3' and reverse, 5'-GGTATCCTCTGTGAAGTCTCCTCTC-3'. PCR cycles were carried out by initial denaturation at $95^{\circ} \mathrm{C}$ for $5 \mathrm{~min}$, then running 40 cycles of $95^{\circ} \mathrm{C}$ for $10 \mathrm{sec}$ and $60^{\circ} \mathrm{C}$ for $1 \mathrm{~min}$. Duplicate experiments were conducted to calculate the mean $\Delta \Delta \mathrm{Cq}$, mean RQ (fold-change) and standard deviation.

ELISA. The level of each protein, TGF- $\beta$, IL-1 $\beta$, IL-10, IL-6 and TNF- $\alpha$, was determined with ELISA, using the following commercial kits: TGF- $\beta$ Quantikine ELISA kit (cat. no. MB100B; R\&D Systems, Inc, Minneapolis, MN, USA), IL-1 $\beta$ Quantikine ELISA kit (cat. no. MLB00C; R\&D Systems, Inc.), IL-10 Quantikine ELISA kit (cat. no. M1000B; R\&D Systems, Inc.), LL-6 Quantikine ELISA kit (cat. no. M6000B; R\&D Systems, Inc.) and TNF- $\alpha$ Quantikine ELISA kit (cat. no. MB100B; R\&D Systems, Inc.) Briefly, $100 \mu 1$ of each standard and sample were incubated with pre-coated antibody plates for $2.5 \mathrm{~h}$ at RT with gentle agitation. Following an extensive wash with the provided buffer, $100 \mu \mathrm{l}$ of biotinylated antibody were added to the wells for $1 \mathrm{~h}$ at RT with gentle shaking. The amount of cytokine present in the sample or standard solution present in each well was then determined by incubating the previous mix with $100 \mu \mathrm{l}$ of streptavidin solution for $45 \mathrm{~min}$ at RT and then with $100 \mu 1$ of TMB One-Step substrate reagent. The colorimetric reaction was stopped after $30 \mathrm{~min}$ of incubation at RT by adding $50 \mu \mathrm{l}$ of stop solution to each well. The absorbance at $450 \mathrm{~nm}$ was immediately measured using a microplate reader (Bio-Rad, Hercules, CA, USA).

Statistical analysis. Results were presented as means \pm standard error of the mean, and all the analysis were performed
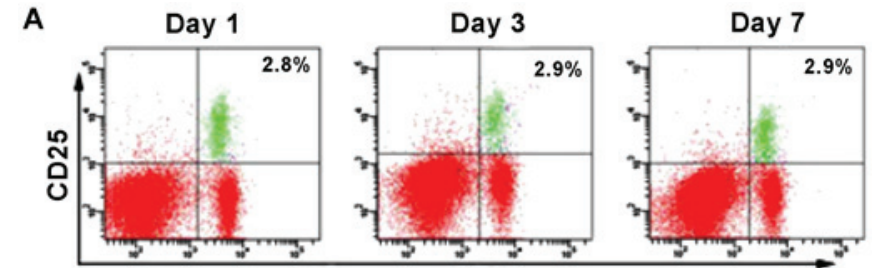

B

CD4
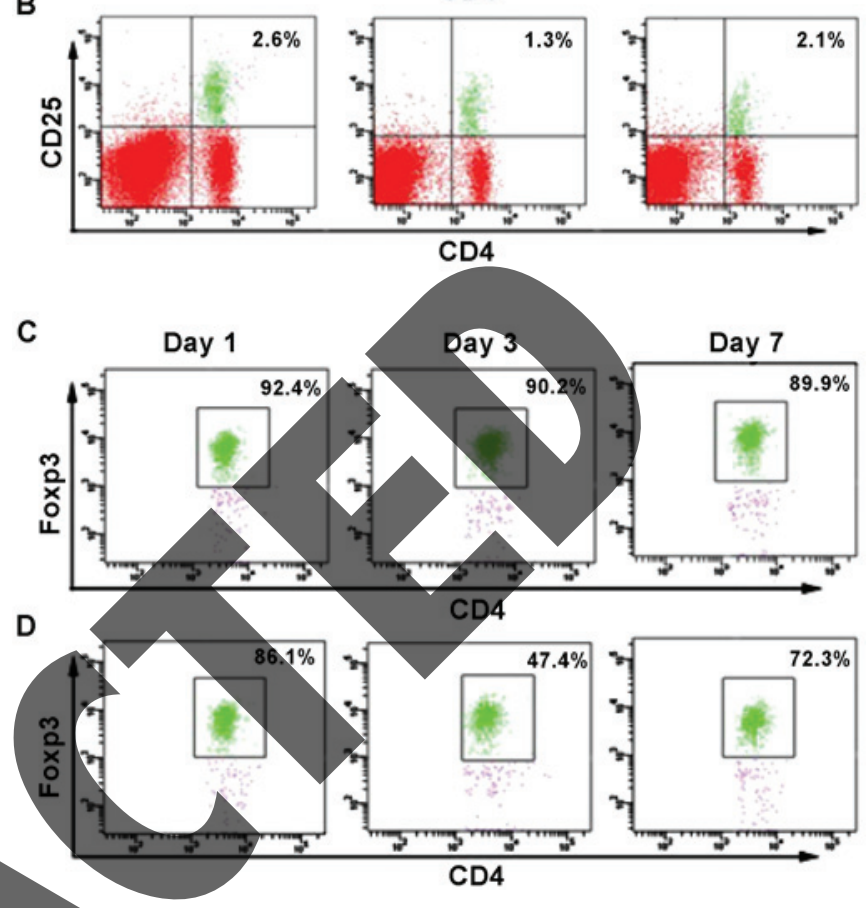

Figure 1. Percentage of Tregs was considerably reduced at day 3 post-traumatic brain injury (TBI) induction. Analysis of the Treg concentrations 1,3 and 7 days following TBI induction. Flow cytometry analysis of $\mathrm{CD} 25^{+} \mathrm{CD} 4^{+}$cells in the sham group; (B) $\mathrm{CD} 25^{+} \mathrm{CD} 4^{+}$cells in the TBI roup; (C) FoxP3 $3^{+} \mathrm{CD} 4^{+}$cells in the sham group; (D) FoxP3 $3^{+} \mathrm{CD} 4^{+}$cells in the TBI group results show that the percentage of Tregs was considerably reduced at day 3 post-TBI induction.

using GraphPad Prism software (GraphPad Software, Inc., San Diego, CA, USA) and SPSS 17.0 (SPSS, Inc., Chicago, IL, USA). Categorical variables were compared using Pearson Chi-square test, continuous variables between groups were compared using Student's t-test or ANOVA. The numbers of circulating Tregs at different time points were compared using ANOVA. $\mathrm{P}<0.05$ was considered to indicate a statistically significant difference.

\section{Results}

A previous report (12) evidenced a reduced number of circulating Treg cells when patients suffered from TBI, compared to healthy individuals. However, it is unknown at which time point the number of Tregs is significantly affected by the presence of TBI. Therefore, we conducted flow cytometry analysis to determine the percentage of $\mathrm{CD} 4{ }^{+} \mathrm{CD} 25^{+} \mathrm{FoxP}^{+}$cells at different days after the brain injury (Fig. 1B and D), and compared these values with the number of cells present in the sham control group (Fig. 1A and C). No significant change in the percentage of $\mathrm{CD}^{+}{ }^{+} \mathrm{FoxP}^{+}$and $\mathrm{CD} 4^{+} \mathrm{CD} 25^{+}$cells was observed in the sham group. However, at day 1 after TIB induction, the 

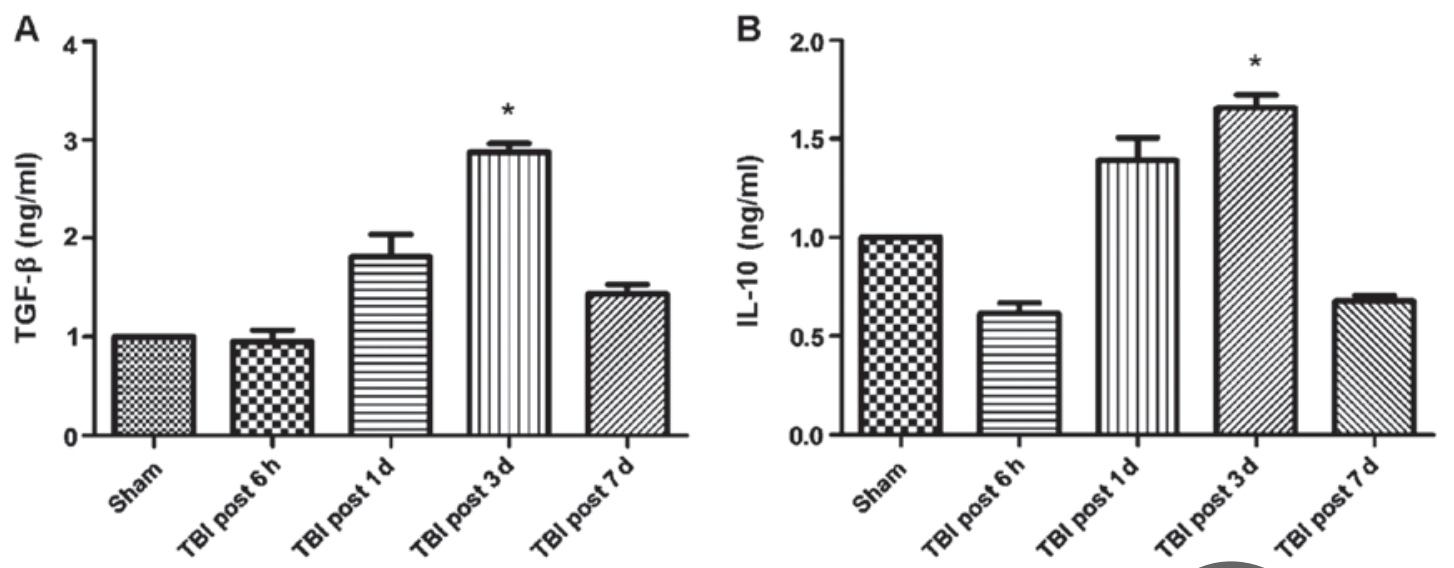

Figure 2. Increased expression of anti-inflammatory cytokines at day 3 post-traumatic brain injury (TBI). (A) Transforming growth factor (TGF)- $\beta$ levels at different days after TBI development. (B) Interleukin (IL)-10 levels at different days after TBI development. "P<Q.0.5.

percentage of FoxP $3^{+}$cells was reduced to $1.3 \%$ compared to $2.6 \%$, which corresponded to the sham group. Similarly, the percentage of $\mathrm{CD}^{+}{ }^{+} \mathrm{CD} 25^{+}$cells was reduced to $47.4 \%$, compared to $86.1 \%$ (sham group). However, the percentage of the two cell populations increased at day 7 post-induction of TBI, as a difference with the observed values at day 1 . Thus, the results suggested that between 1 and 7 days following TBI, the number of FoxP3 $3^{+}$cells was significantly reduced in the mouse brain, with a difference from the control group. Notably, this decrease was more pronounced at day 3 post-induction of TBI (Fig. 1). These results also correlated with changes in cytokine levels. Specifically, the expression of the anti-inflammatory cytokines TGF- $\beta$ and IL-10 increased over time following TBI induction, whereas the expression of pro-inflammatory cytokines TNF- $\alpha$, IL- $1 \beta$ and IL- 6 was significantly reduced (Figs. 2 and 3). Of note, this effect was more pronounced at 3 days post-induction of TBI, compared to 7 days. In addition, IHC staining for FoxP3 revealed that the expression of FoxP3 in the two TBI groups, contralateral and ipsilateral (Fig. 4), were significantly increased compared with the sham group.

Pre-clinical and clinical studies have peported that TBI can induce chronic, as well as acute neuro-degeneration. Among classical chronic neurodegenerative dísorders, microglial activation has been identified to contribute to delayed cell death and tissue loss. Therefore, we examined the microglia cell involvement in this condition. As shown in Fig. 5, our data suggested that the activation of microglia cells was significantly higher at 1 day post-TBI, compared to the levels observed in the sham group.

In the animal model of cerebral hemorrhage, investigators found that the proliferation of Tregs after active immunization can stimulate the secretion of large amount of anti-inflammatory cytokines, thereby suppressing inflammatory reactions and mitigating tissue damage. Subsequently, the compromised neuro-functions were safeguarded effectively. In order to determine whether Tregs render a neuro-protective effect in the presence of TBI, we isolated Tregs from mouse spleens and enriched them by magnetic sorting and finally, we injected them back into the brain of mice from the TBI group. After the isolation and enrichment, the percentage of Tregs reached $85.9 \%$ purity (Fig. 6).

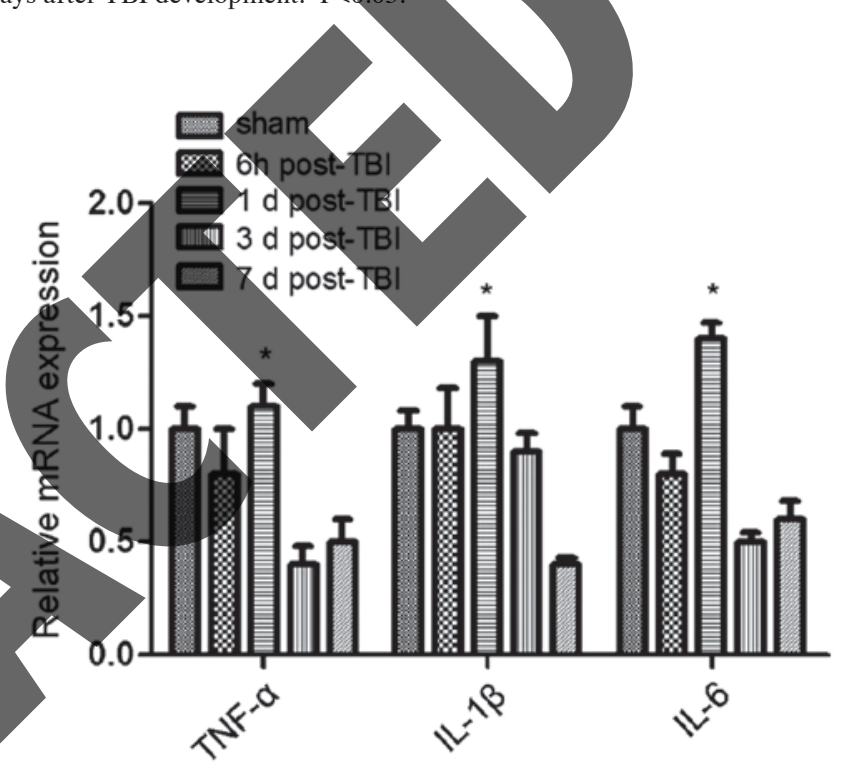

Figure 3. Increased RNA expression of anti-inflammatory cytokines at day 3 post-traumatic brain injury (TBI). qPCR analysis showed that the expression of pro-inflammatory cytokines [tumor necrosis factor (TNF)- $\alpha$, and interleukin (IL)-1 $\beta$, IL-6] was significantly enhanced at day 1 post-induction of TBI $(\mathrm{P}<0.05)$, and reduced gradually afterwards. ${ }^{*} \mathrm{P}<0.05$.

To investigate the role that Tregs play in immune-modulation, we subdivided mice that received the brain injury into five groups: i) Saline group; ii) Tregs depletion group; iii) small-dose (SD) group, treatment with $1.25 \times 10^{5}$ Tregs; iv) moderate-dose (MD) group, treatment with $2.5 \times 10^{5}$ Tregs; and v) large-dose (LD) group, treatment with $5 \times 10^{5}$ Tregs. After TBI development and, following euthanasia, the percentage of Tregs was measured for each group with flow cytometry. According to Fig. 7, the result showed a significant increase of Tregs in all the mouse groups, which received Tregs: $3.9 \%$ (LD), $5.4 \%$ (MD), $4.1 \%$ (HD), compared with the saline (1.9\%) and Treg depleted (0\%) groups. However, the mouse group that received intermediate dose of Tregs showed a higher amount of Treg, rather than the group that received the higher dose.

Furthermore, microglia activation was also evaluated using immunofluorescence. As shown in Fig. 8, levels of microglia activation were correlated with the expression of Tregs. In FoxP3 depletion group, the microglia activation level was the highest. However, as the dose of exogenous injection of Tregs 

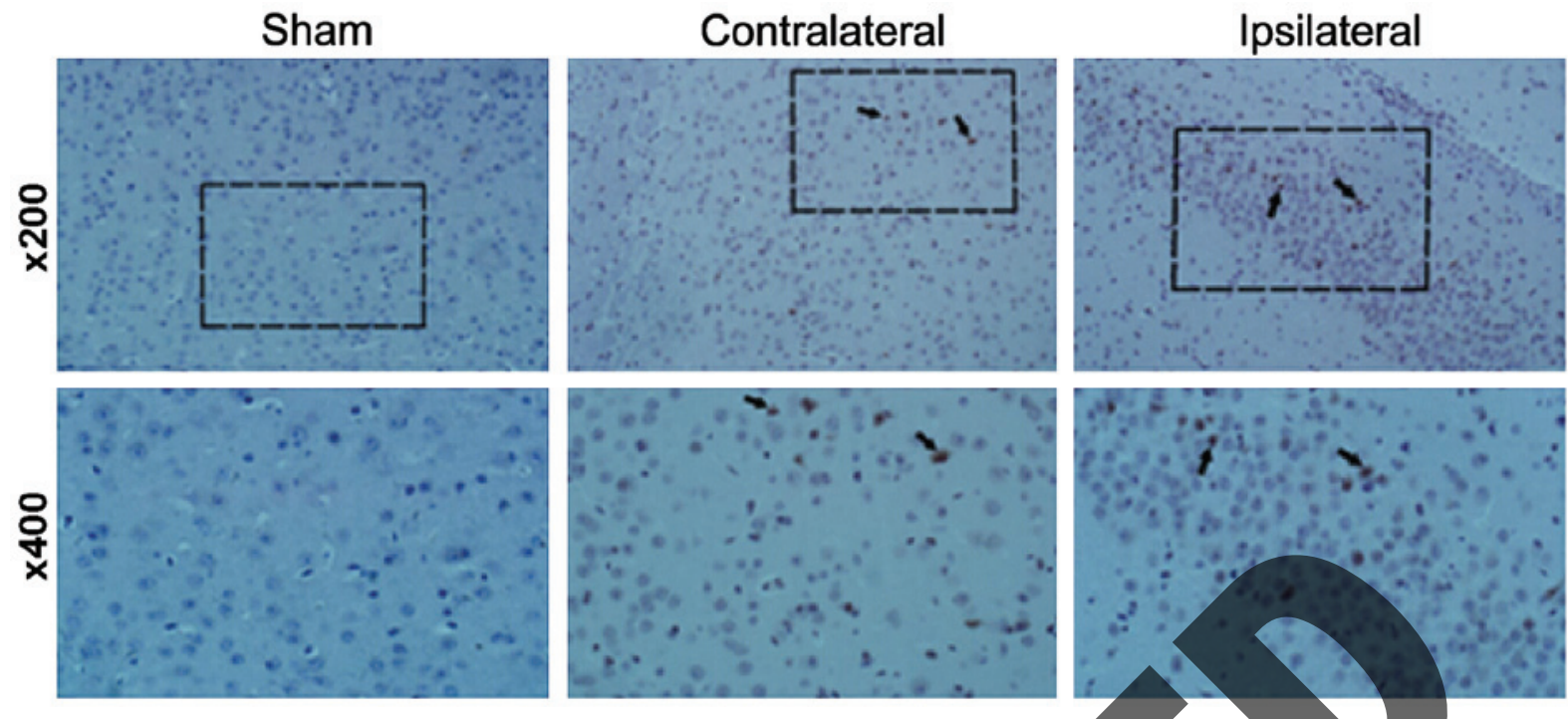

Figure 4. Enhanced detection of FoxP3 in mouse brain tissue sections. IHC staining for FoxP3 revealed that the expression of FoxP3 in both traumatic brain injury groups, contralateral and ipsilateral were significantly increased, as a difference with the levels in the sham brain tissue sections.

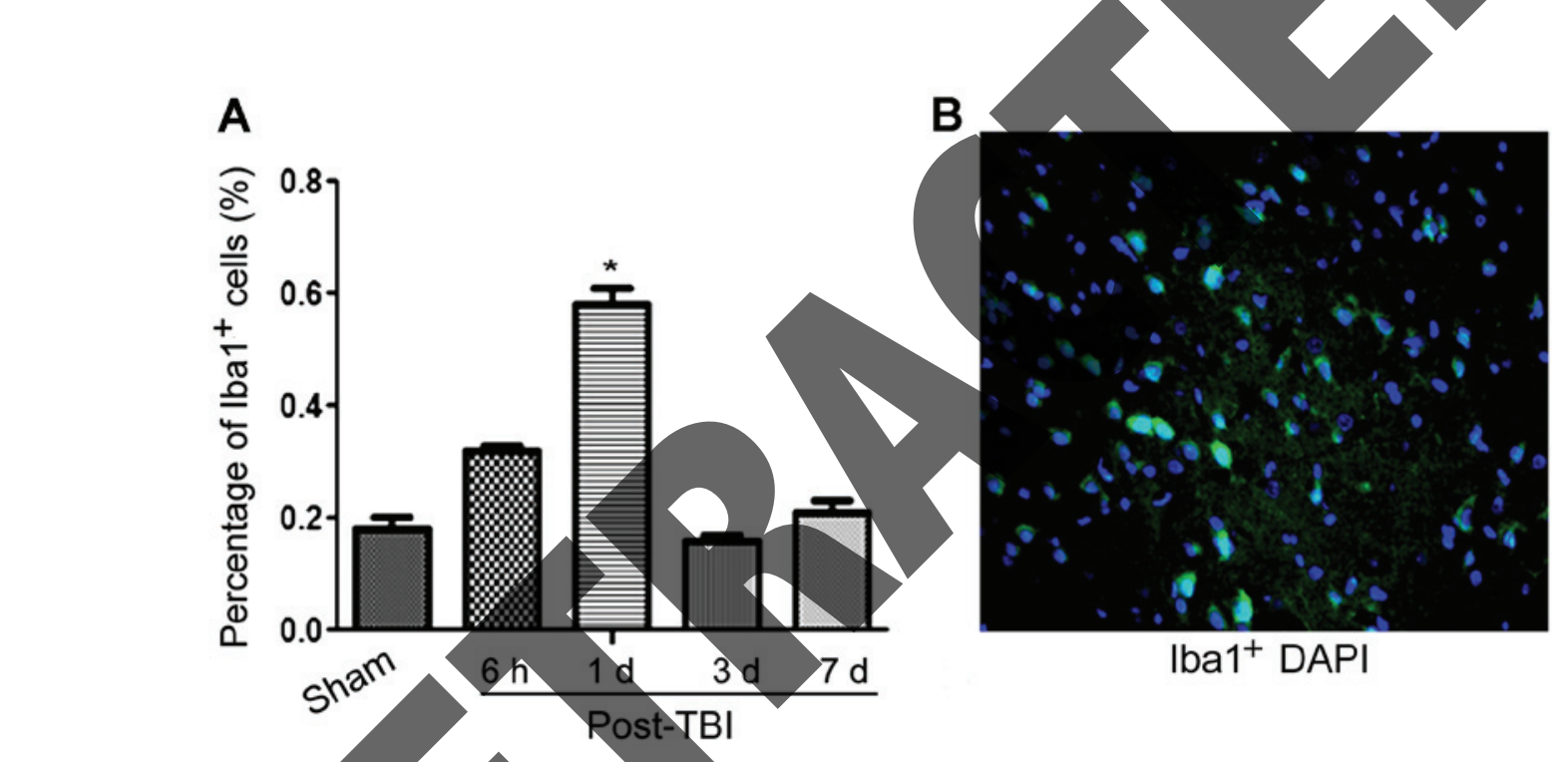

Figure 5. Enhanced activation of Iba1+ cells (microglia) in mouse brain tissue sections. (A) Percentage of Iba1 ${ }^{+}$cells over the time after traumatic brain injury (TBI) development; (B) IF image of Ibal ${ }^{+}$cells (green fluorescence), counterstained with DAPI nuclear staining (blue fluorescence). ${ }^{*} \mathrm{P}<0.05$.

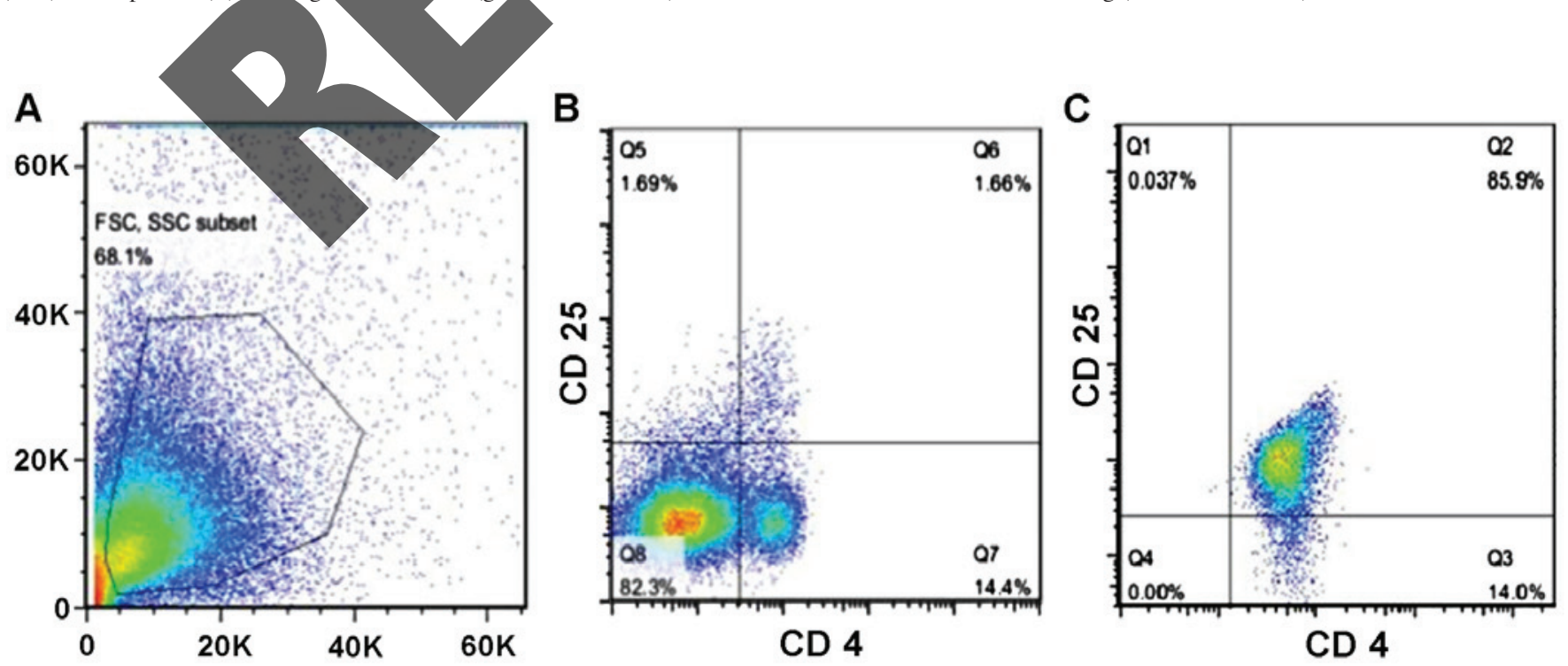

Figure 6. Purity of Tregs following isolation from the mouse spleens. (A) FSC vs. SSC showing the entire cell population in the spleen before purification of Tregs. (B) Analysis of the isolated spleen cells for single CD4 positivity. (C) Analysis of the isolated spleen cells for dual CD4 and CD25 positivity. 
A

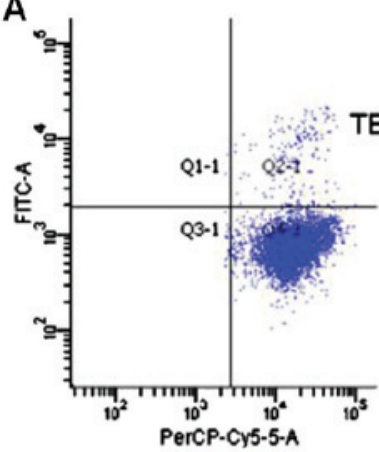

B

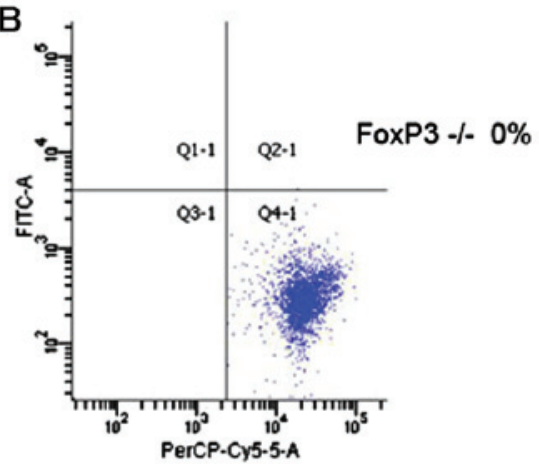

C

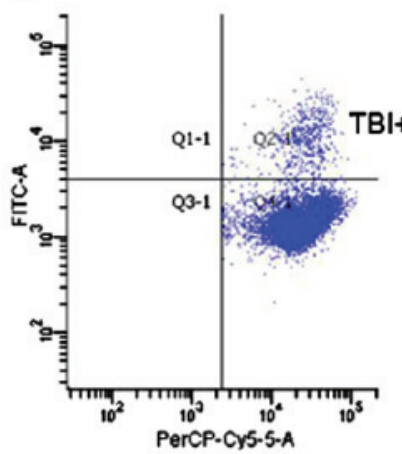

TBI+Saline 1.9\%

D

$E$

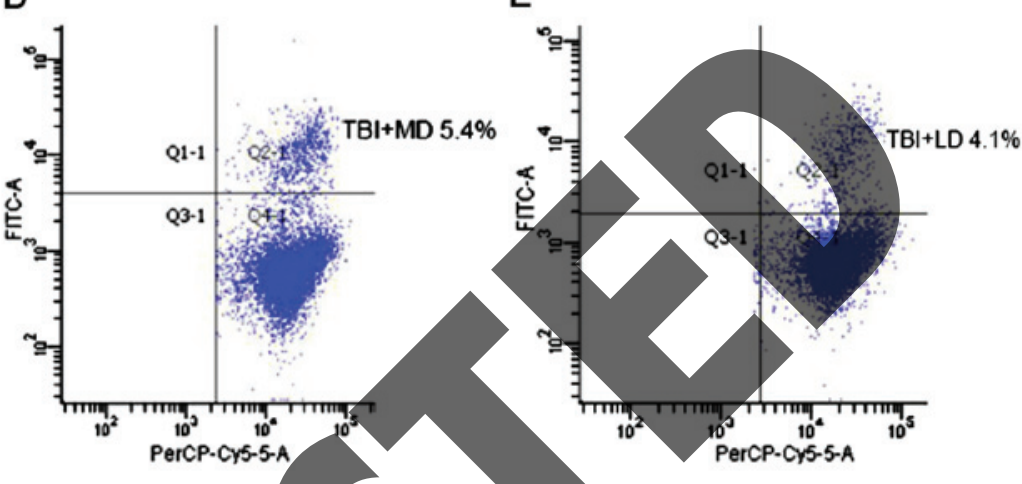

Figure 7. Increase in Tregs levels in mice that received exogenous Treg cells, following induction of traumatic brain injury (TBI). Flow cytometry diagram showing (A) the number of Tregs in the TBI group that received saline injection, (B) the number of Tregs in the TBI group with depleted Tregs, (C) the number of Tregs in the TBI group that received small dose of Tregs injection, (D) the number of Tregs in the TBI group that received intermediate dose of Treg injection, and (E) the number of Tregs in the TBI group that received high dose of Treg injection. SD, small-dose; MD, moderate-dose; LD, large-dose.

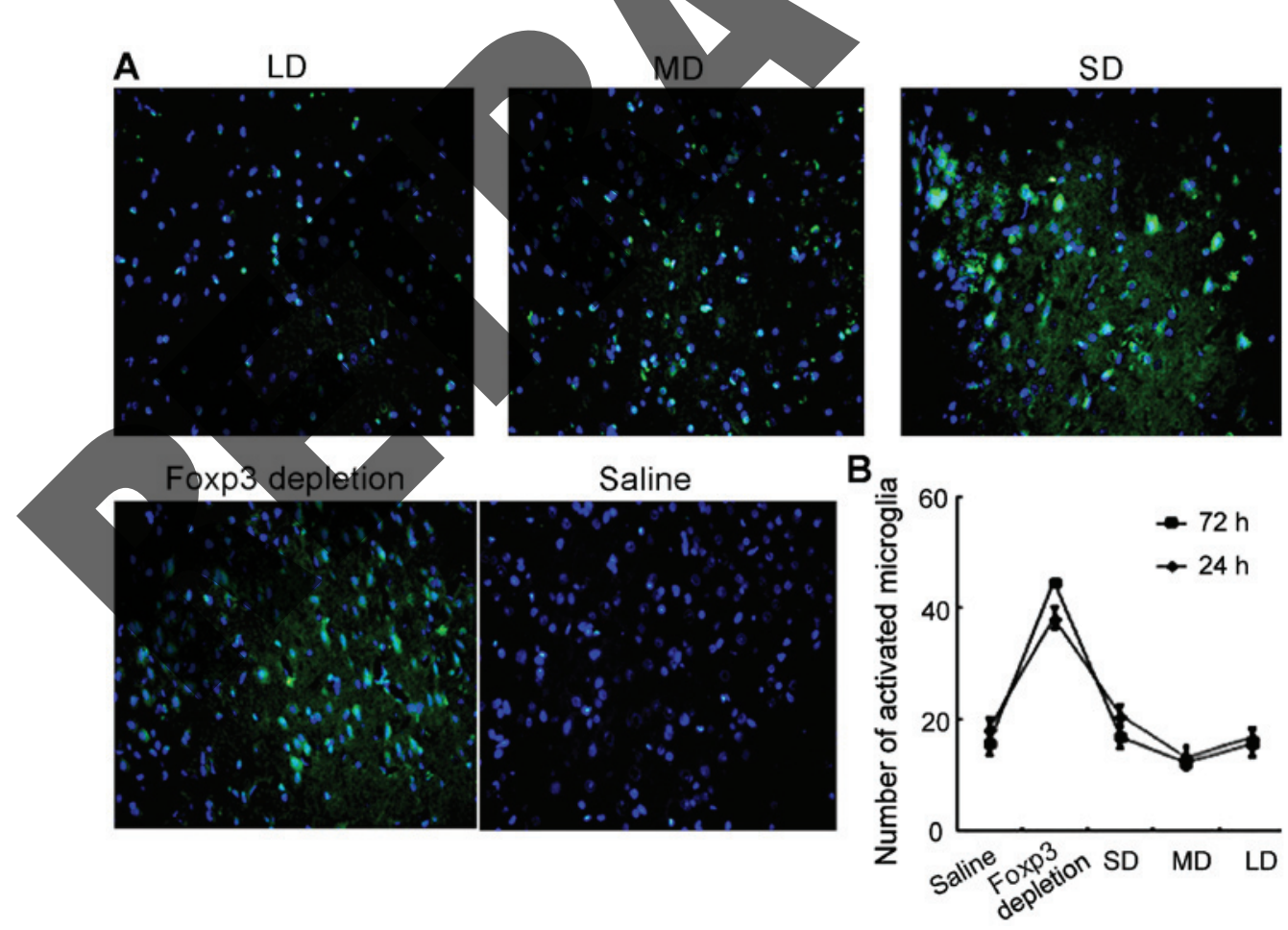

Figure 8. Decrease in activated microglia in mice that received exogenous Treg cells, following induction of traumatic brain injury. (A) Immunofluorescence images showing the number of activated microglia (green fluorescence) in brain tissues from animals of each group: saline, FoxP3 depleted and Tregs at small, medium and high levels. (B) Number of activated microglia in each mice group at 24 and 72 h. SD, small-dose; MD, moderate-dose; LD, large-dose.

continued to increase, the activation of microglia cells was suppressed. In the MD group, the microglia activation level was the lowest.
The degree and progression of inflammatory reactions were evaluated by measuring the expression levels of pro- and anti-inflammatory cytokines, using ELISA and PCR. Our 
A
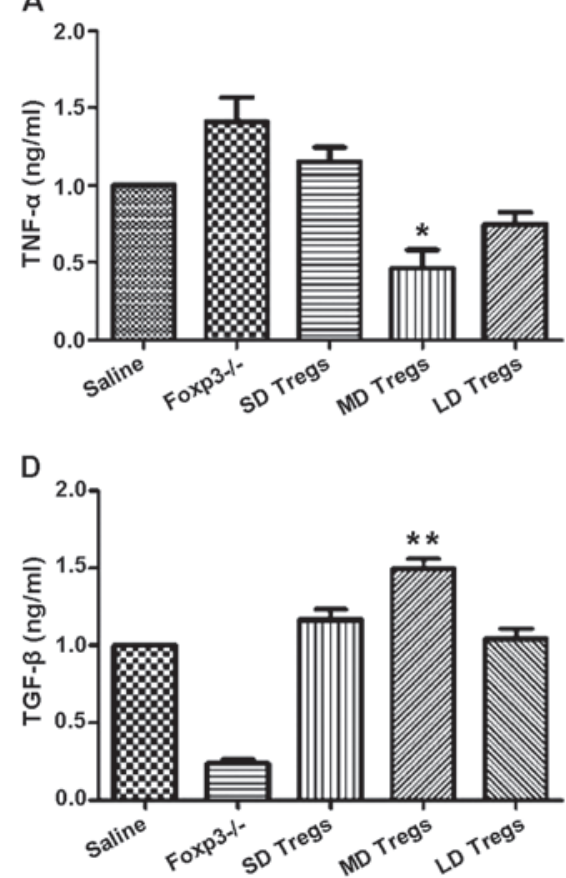

B

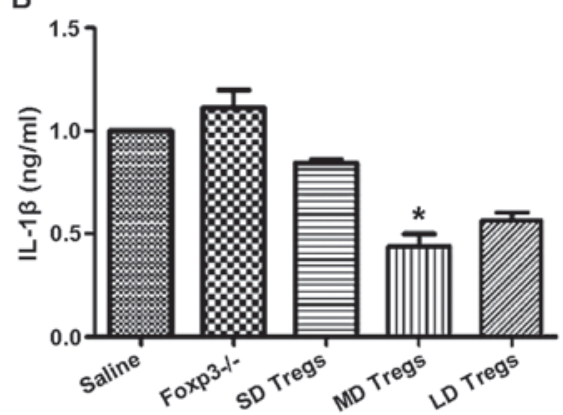

C

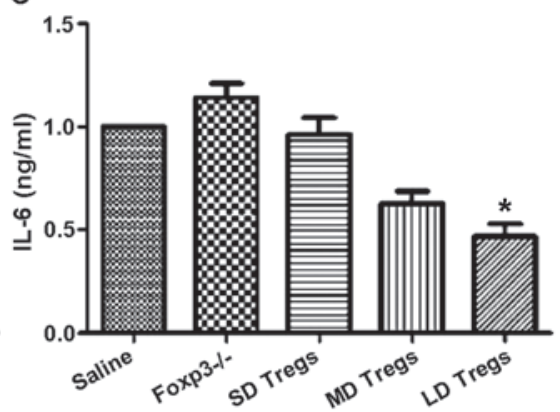

E

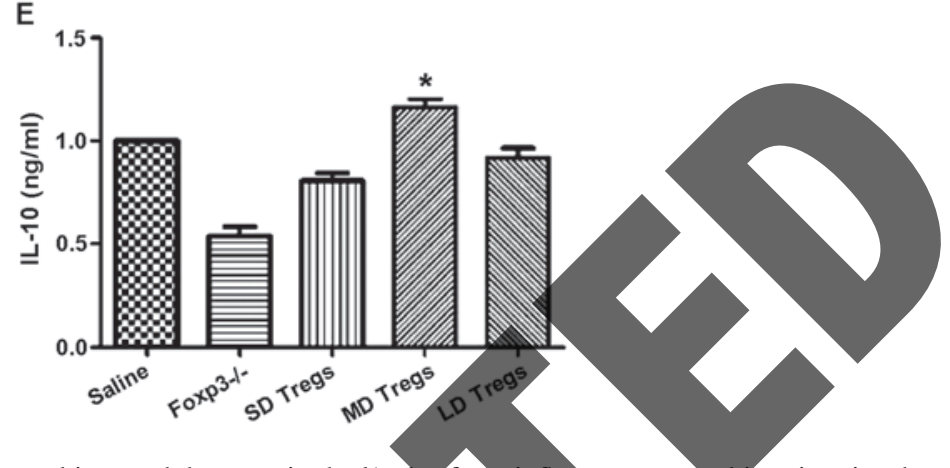

Figure 9. Increase in the levels of anti-inflammatory cytokines and decrease in the levels of pro-inflammatory cytokines in mice that received exogenous Treg cells, following induction of TBI. ELISA analysis show that the expression of (A)tumor necrosis factor (TNF)- $\alpha$, (B) interleukin (IL)-1 $\beta$, (C) IL-6, (D) transforming growth factor (TGF)- $\beta$, and (E) IL-10 in the different mouse groups. "P<0.05, ${ }^{* *} \mathrm{P}<0.01$. SD, small-dose; MD, moderate-dose; LD, large-dose.

results indicated that the expressions of anti-inflammatory Distinct Treg subsets were found to coexist in the intestinal cytokines (TGF- $\beta$, IL-10) were significantly higher in MD mucosa and mesenteric lymph nodes, including the 'natural' group compared to those of other groups (Fig. 9), the levels and 'adaptive' $\mathrm{CD}_{4}^{+}$forkhead box p3 (Fox P3 ${ }^{+}$) Tregs, of pro-inflammatory cytokines, including IL-6, IL-1 $\beta$, TNF- $\alpha$, as well as Th1 and Th3 cells. Tregs that develop in the thymus were significantly enhanced in FoxP3 depletion groutp (Fig. 9). are commonly known as natural Tregs (nTregs). Previous

Previous studies reported that TBI induces a neuroinflammatory response that involves the infiltration of white blood cells into the CNS and activation of resident microglia. To investigate the correlation between microglia activation and TBI, IHC analysis was conducted in the following group: Saline, Treg depleted and mice injeeted with different concentrations of Tregs, using FoxP3 antibody. The results showed that in the group that received Treg cells, the activation of microglia was enormously hampered, compared to the activation in the csaline group and the Treg depleted group (Fig. 10). Our data revealed that Tregs inhibited the inflammatory response by suppressing the microglia activation.

To elucidate the underlying mechanism of the Treg-mediated immune suppression, we conducted western blot analysis. Specifically, we investigated the JNK-NF- $\kappa B$ signaling pathway. Detections of Erk1/2, p38 MAPK, NF-kB and JNK1 at the protein level were performed. Our results indicated that the expression levels of p-Erk1/2, p-p38 MAPK, p-NF- $\kappa B$ and p-JNK were significantly reduced in the groups treated with Tregs, especially in the MD group (Fig. 11), while the expression of total Erk1/2, p38 MAPK, NF-kB and JNK1 remained constant. These results indicated that Tregs suppressed inflammatory reactions by inhibiting the JNK-NF- $\mathrm{BB}$ pathway.

\section{Discussion}

Regulatory pathways mediated by Tregs constitute an essential homeostatic mechanism of the immune system (7-12).

lation, and in and several signaling pathways $(23,24)$.

Inflammation is characterized by an interplay modulation of pro- and anti-inflammatory cytokines. Cytokines are commonly classified as pro-inflammatory: IL-1, TNF, interferon (IFN)- $\gamma$, IL-12, IL-18, whereas, IL-4, IL-10, IL-13, IFN- $\alpha$ and TGF- $\beta$ are considered anti-inflammatory cytokines (25-31). In the present study, the inflammatory response was evaluated by comparing the expression levels of anti-inflammatory cytokines (IL-10, TGF- $\beta$ ) and pro-inflammatory cytokines (TNF- $\alpha$, IL-1 $\beta$, IL-6) between TBI and Sham groups, using qPCR and ELISA analysis. Our data suggested that the expression of IL-10 and TGF- $\beta$ was significantly lower in TBI group compared with those in the sham group, while the expression of TNF- $\alpha$, IL- $1 \beta$, IL- 6 was significantly higher in the injured group compared with their expression in the sham group. However, after increasing the concentration of Tregs in the TBI group, the expression of IL-10 and TGF- $\beta$ was enhanced, while the expression of TNF- $\alpha$, IL- $1 \beta$, and IL-6 was decreased, compared to the sham group (32-36). Therefore, we concluded that the development of TBI can elicit an inflammatory reaction, albeit its effect can be neutralized and may even be reversed by the presence of Tregs.

The CNS is considered an immune-privileged site because the entry of lymphocytes to this area is tightly controlled by the endothelial blood-brain barrier (BBB) and blood-spinal cord barrier (BSCB) (27-29). Under normal conditions, the number 

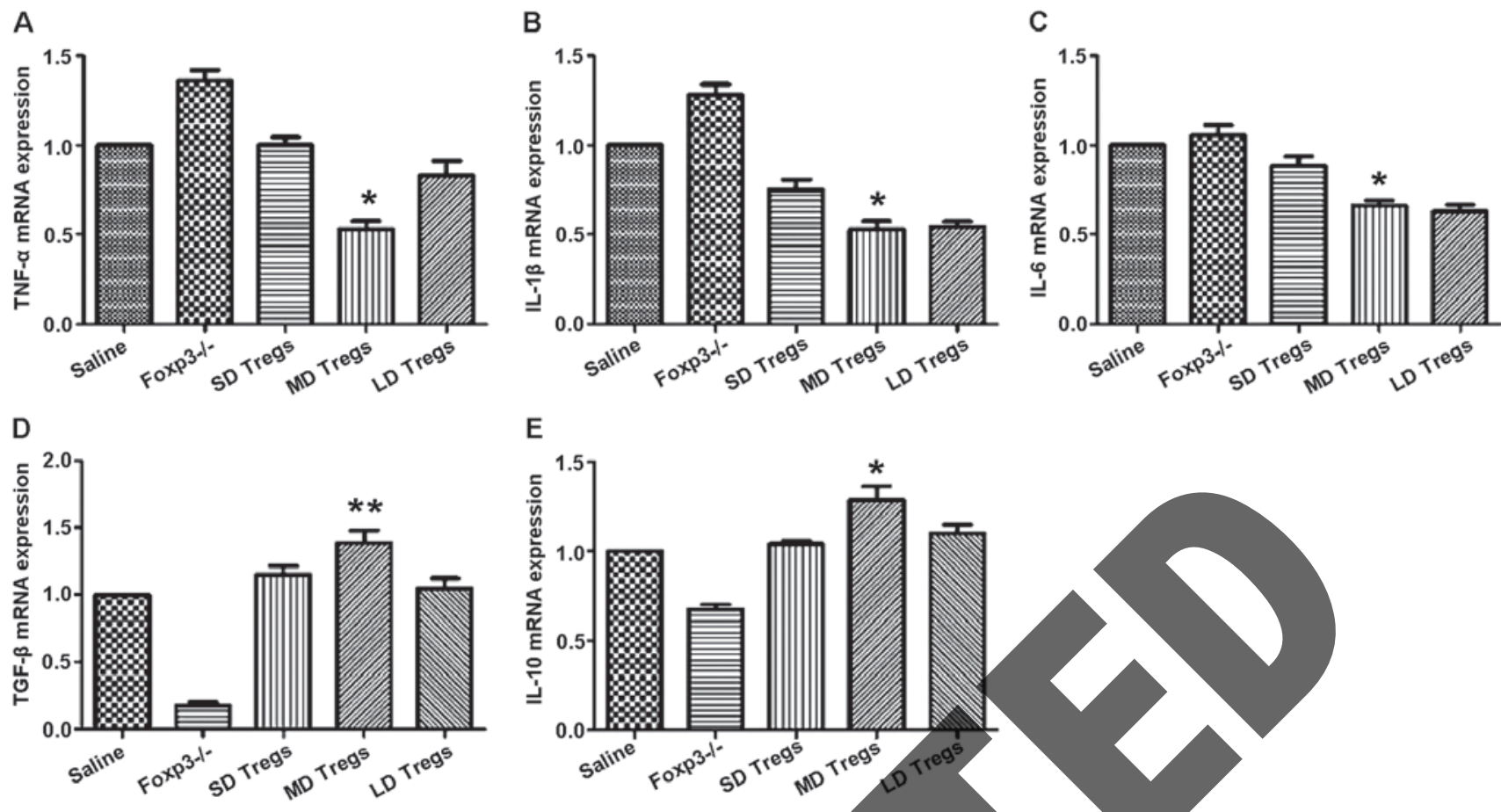

Figure 10. Increase in the transcript levels of anti-inflammatory cytokines and decrease in the transcripts levels of pro-inflammatory cytokines in mice that received exogenous Treg cells, following induction of traumatic brain injury. qPCR analysis showing the transcript expression of (A) tumor necrosis factor (TNF)- $\alpha$, (B) interleukin IL-1 $\beta$, (C) IL-6, (D) transforming growth factor (TGF)- $\beta$, and (E) IL-10 in the different mouse groups. ${ }^{*}<0.05,{ }^{* *} \mathrm{P}<0.01$. SD, small-dose; MD, moderate-dose; LD, large-dose.

A

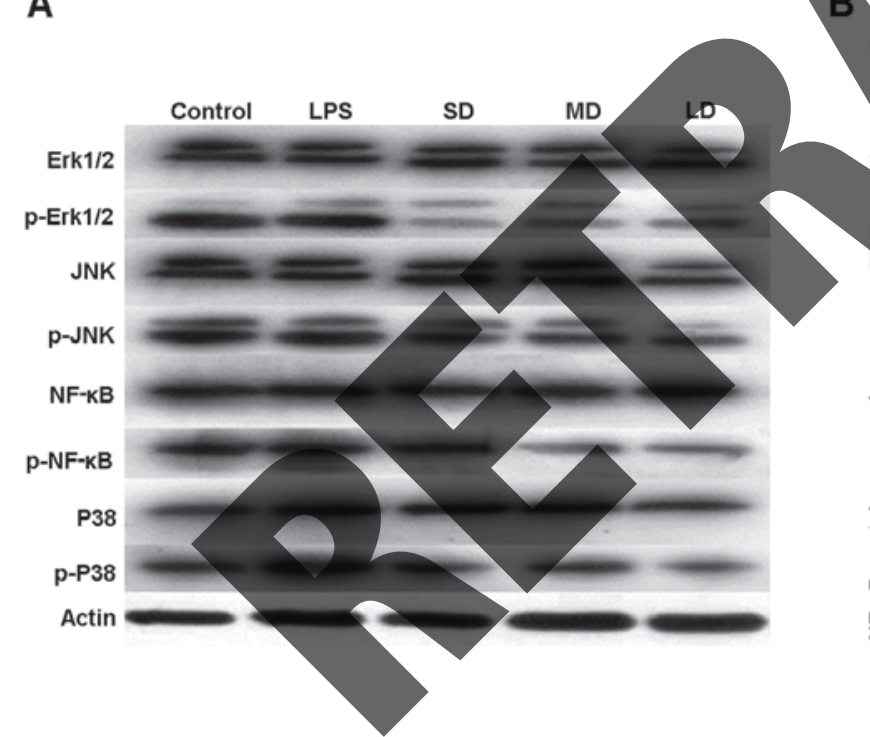

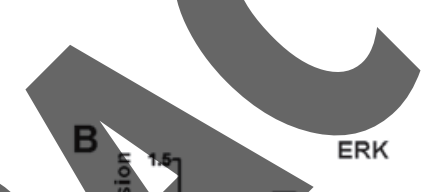

ERK
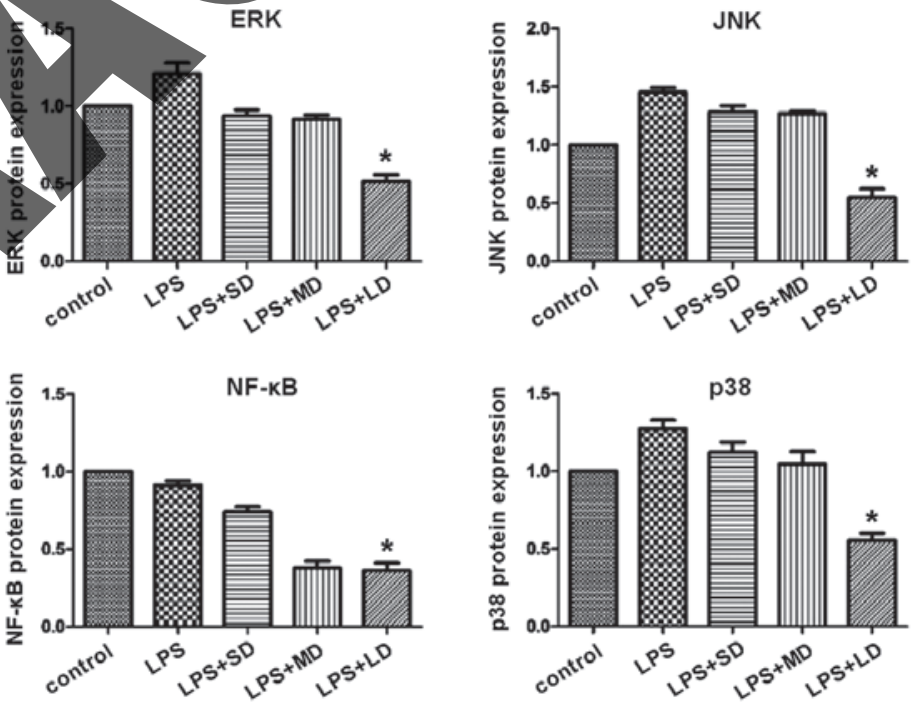

Figure 11. p-erk1/2, p-p38 MAPK, p-NF- $\mathrm{B}$ and p-JNK protein expression, respectively, significantly reduced in the mouse groups treated with Tregs. (A) Western blot analysis showing the protein expression of p-Erk1/2, p-JNK, p-NF- $\mathrm{B}$, and p-p38 MAPK. (B) Quantification of the protein levels for p-Erk1/2, p-JNK, p-NF- $\mathrm{B}$, and p-p38 MAPK in the different mouse groups. "P<0.05. SD, small-dose; MD, moderate-dose; LD, large-dose.

of leukocytes travelling into the CNS is small, however, in the presence of TBI and its associated secondary inflammatory reaction, a large number of circulating immunocompetent cells readily gain access into the CNS. This enhanced vascular permeability and increased leukocyte cell infiltration into the CNS during TBI is due to severe BBB and BSCB alterations.

Besides the leukocytes infiltration into the CNS, inducible Tregs (iTregs) are also developed from naïve CD4 T cells (nTregs) in the lymphoid tissues (37). This induction takes place in response to an adequate antigen stimulation and in the presence of anti-inflammatory cytokines, such as TGF- $\beta$ and IL-10, while in the absence of pro-inflammatory cytokines such as IL-6, IL-12 and IFN- $\gamma$. By contrast, after TBI, Treg levels are significantly increased, possibly due to the trafficking of nTregs and iTregs into the CNS (22).

Microglia, a common immune cell that resides in the CNS, has been also involved in the TBI pathophysiology. Microglia are considered a source of highly cytotoxic substances. By 
delivering deriving oxygen-free radicals, subsequent reaction products, hydrogen peroxide and peroxynitrite, microglia are potentially able to injure cells, produce oxidative damage and induce neurodegeneration. Increased immunoreactivity in the brain was detected after TBI, followed by the accumulation and activation of microglia cells $(25,30)$.

To investigate the interplay between Tregs and microglia cells, we conducted an experiment consisting of five groups: i) Saline (control), ii) TBI, iii) TBI+SD Treg, iv) TBI+MD Tregs, and v) TBI+LD Tregs. In the TBI group, the maximized effect of accumulation and activation of microglia cells was observed, while, in the TBI+SD Treg group, microglia activation induced by TBI was suppressed, compared to the control group. Similar trend was detected using the IHC method. Accordingly, qPCR and ELISA analysis confirmed that the expression of pro-inflammatory cytokines (TNF- $\alpha$, IL-1 $\beta$, and IL-6) in the TBI group were significantly higher than that in any other group, while the expression of TNF- $\alpha$, IL- $1 \beta$, and IL-6 was significantly decreased in the TBI+MD Tregs group. The results were consistent with the results of Sakaguchi (31). Our experiments showed that Tregs suppress the inflammatory response, thereby exhibiting neuroprotective effects and improving prognosis of TBI in the mouse model.

The current study focused on identifying the immunomodulatory role of Tregs in the mouse model of TBI, confirming the immune suppressive and neuroprotective functions of Tregs. The findings of the present study provide theoretically basis for the development of novel methods for TBI management and treatment.

\section{Acknowledgements}

The present study was supported by Scientific Award for Society Developm

\section{References}

1. Brasure M, Lamberty Ouellette $\mathrm{J}$ and Wilt rehabilitation for mode in adults: a sys $1398-1420,2013$

2. Faden AI: Microglial activation and traumatic brain injury. Ann Neurol 70:

3. Whalen MJ, Carlos TM, Wisniewski SR, Clark RS, Mellick JA, Marion DW and Kochanek PM. Effect of neutropenia and granulocyte colony stimulating factor-induced neutrophilia on blood-brain barrier permeability and brain edema after traumatic brain injury in rats. Crit Care Med 28: 3710-3717, 2000.

4. Ahn MJ, Sherwood ER, Prough DS, Lin CY and DeWitt DS: The effects of traumatic brain injury on cerebral blood flow and brain tissue nitric oxide levels and cytokine expression. $\mathrm{J}$ Neurotrauma 21: 1431-1442, 2004

5. Readnower RD, Chavko M, Adeeb S, Conroy MD, Pauly JR, McCarron RM and Sullivan PG: Increase in blood-brain barrier permeability, oxidative stress, and activated microglia in a rat model of blast-induced traumatic brain injury. J Neurosci Res 88: 3530-3539, 2010.

6. Liesz A, Suri-Payer E, Veltkamp C, Doerr H, Sommer C, Rivest S, Giese T and Veltkamp R: Regulatory T cells are key cerebroprotective immunomodulators in acute experimental stroke. Nat Med 15: 192-199, 2009.

7. Ishibashi S, Maric D, Mou Y, Ohtani R, Ruetzler C and Hallenbeck JM: Mucosal tolerance to E-selectin promotes the survival of newly generated neuroblasts via regulatory T-cell induction after stroke in spontaneously hypertensive rats. J Cereb Blood Flow Metab 29: 606-620, 2009.
8. Shi Y, Fukuoka M, Li G, Liu Y, Chen M, Konviser M, Chen X, Opavsky MA and Liu PP: Regulatory T cells protect mice against coxsackievirus-induced myocarditis through the transforming growth factor $\beta$-coxsackie-adenovirus receptor pathway. Circulation 121: 2624-2634, 2010.

9. Strisciuglio $\mathrm{C}$ and van Deventer S: Regulatory T cells as potential targets for immunotherapy in inflammatory bowel disease. Immunotherapy 2: 749-752, 2010.

10. Liu R, Zhou Q, La Cava A, Campagnolo DI, Van Kaer L and Shi FD: Expansion of regulatory T cells via IL-2/anti-IL-2 mAb complexes suppresses experimental myasthenia. Eur J Immunol 40: 1577-1589, 2010.

11. Meng X, Zhang K, Li J, Dong M, Yang J, An G, Qin W, Gao F, Zhang $C$ and Zhang Y: Statins induce the accumulation of regulatory $\mathrm{T}$ cells in atherosclerotic plaque. Mol Med 18: 598-605, 2012.

12. Li M, Lin YP, Chen JL, Li H, Jiang RC and Zhang JN: Role of regulatory $\mathrm{T}$ cell in clinical outcome of traumatic brain injury.

Chin Med J (Engl) 128: 1072-1078, 2015 .
13. Sakaguchi S, Sakaguchi N, Asano M, Itoh M and Toda M: Immunologic self-tolerance maintained by activated $T$ cells expressing IL-2 receptor alpha-chains (CD25). Breakdown of a single mechanism of self-tolerance causes various autoimmune diseases. J Immunol 155: 1151-1164, 1995

14. Sakaguchi S, Miyara M, Costantino CM and Hafler DA: FOXP3 ${ }^{+}$ regulatory $T$ cells in the human immune system. Nat Rev Immunol 10:

15. Vignali DA,Collison LW and Workman CJ: How regulatory T cells work. Nat Rev Immunol 8: 523-532, 2008.

16. Yuan R, Maeda Y, Li W, Lu W, Cook S and Dowling P: Erythropoletin: A potent inducer of peripheral immuno/inflammatory modulation in autoimmune EAE. PLoS One 3: e1924, 008.

Dénes A, Humphreys N, Lane TE, Grencis R and Rothwell N: Chronic systemic infection exacerbates ischemic brain damage via a CCL5 (regulated on activation, normal T-cell expressed and secreted)-mediated proinflammatory response in mice. J Neurosci 30. 10086-10095, 2010.

Bassil R, Zhu B, Lahoud Y, Riella LV, Yagita H, Elyaman W and Khoury SJ: Notch ligand delta-like 4 blockade alleviates experimental autoimmune encephalomyelitis by promoting regulatory T cell development. J Immunol 187: 2322-2328, 2011.

Louveau A, Smirnov I, Keyes TJ, Eccles JD, Rouhani SJ, Peske JD, Derecki NC, Castle D, Mandell JW, Lee KS, et al: Structural and functional features of central nervous system lymphatic vessels. Nature 523: 337-341, 2015.

20. Sakaguchi S, Ono M, Setoguchi R, Yagi H, Hori S, Fehervari $\mathrm{Z}$, Shimizu J, Takahashi T and Nomura T: Foxp3 ${ }^{+} \mathrm{CD} 25^{+} \mathrm{CD} 4^{+}$ natural regulatory $\mathrm{T}$ cells in dominant self-tolerance and autoimmune disease. Immunol Rev 212: 8-27, 2006.

21. Ghajar J: Traumatic brain injury. Lancet 356: 923-929, 2000.

22. Ziebell JM and Morganti-Kossmann MC: Involvement of pro- and anti-inflammatory cytokines and chemokines in the pathophysiology of traumatic brain injury. Neurotherapeutics 7: 22-30, 2010.

23. Scheffold A, Murphy KM and Hofer T: Competition for cytokines: T(reg) cells take all. Nat Immunol 8: 1285-1287, 2007.

24. Zhang Q, Cui F, Fang L, Hong J, Zheng B and Zhang JZ: TNF-alpha impairs differentiation and function of TGF-betainduced Treg cells in autoimmune diseases through Akt and Smad3 signaling pathway. J Mol Cell Biol 5: 85-98, 2013.

25. Nagamoto-Combs K, McNeal DW, Morecraft RJ and Combs CK: Prolonged microgliosis in the rhesus monkey central nervous system after traumatic brain injury. J Neurotrauma 24: 1719-1742, 2007.

26. Abbott NJ: Inflammatory mediators and modulation of blood-brain barrier permeability. Cell Mol Neurobiol 20: 131-147, 2000.

27. Amiry-Moghaddam M and Ottersen OP: The molecular basis of water transport in the brain. Nat Rev Neurosci 4: 991-1001, 2003.

28. Balda MS, Whitney JA, Flores C, González S, Cereijido M and Matter K: Functional dissociation of paracellular permeability and transepithelial electrical resistance and disruption of the apical-basolateral intramembrane diffusion barrier by expression of a mutant tight junction membrane protein. J Cell Biol 134: 1031-1049, 1996.

29. Di Giovanni S, Movsesyan V, Ahmed F, Cernak I, Schinelli S, Stoica B and Faden AI: Cell cycle inhibition provides neuroprotection and reduces glial proliferation and scar formation after traumatic brain injury. Proc Natl Acad Sci USA 102: 8333-8338, 2005. 
30. Ramlackhansingh AF, Brooks DJ, Greenwood RJ, Bose SK, Turkheimer FE, Kinnunen KM, Gentleman S, Heckemann RA, Gunanayagam K, Gelosa G, et al: Inflammation after trauma: Microglial activation and traumatic brain injury. Ann Neurol 70 374-383, 2011

31. Sakaguchi S: Naturally arising Foxp3-expressing CD $25^{+} \mathrm{CD} 4^{+}$ regulatory $\mathrm{T}$ cells in immunological tolerance to self and non-self. Nat Immunol 6: 345-352, 2005.

32. Schwartz RH: Natural regulatory T cells and self-tolerance. Nat Immunol 6: 327-330, 2005.

33. La Cava A, Van Kaer L and Fu-Dong-Shi: CD $4^{+} \mathrm{CD} 25^{+}$Tregs and NKT cells: Regulators regulating regulators. Trends Immunol 27: 322-327, 2006

34. Balandina A, Lécart S, Dartevelle P, Saoudi A and Berrih-Aknin S: Functional defect of regulatory CD4(+)CD25(+) $\mathrm{T}$ cells in the thymus of patients with autoimmune myasthenia gravis. Blood 105: 735-741, 2005.
35. Fattorossi A, Battaglia A, Buzzonetti A, Ciaraffa F, Scambia G and Evoli A: Circulating and thymic CD4 CD25 T regulatory cells in myasthenia gravis: Effect of immunosuppressive treatment. Immunology 116: 134-141, 2005.

36. Liu R, La Cava A, Bai XF, Jee Y, Price M, Campagnolo DI, Christadoss P, Vollmer TL, Van Kaer L and Shi FD: Cooperation of invariant NKT cells and $\mathrm{CD} 4{ }^{+} \mathrm{CD} 25^{+} \mathrm{T}$ regulatory cells in the prevention of autoimmune myasthenia. J Immunol 175: 7898-7904, 2005

37. Ji J and Cloyd MW: HIV-1 binding to CD4 on CD4+CD25+ regulatory $\mathrm{T}$ cells enhances their suppressive function and induces them to home to, and accumulate in, peripheral and mucosal lymphoid tissues: An additional mechanism of immunosuppression. Int Immunol 21: 283-294, 2009.

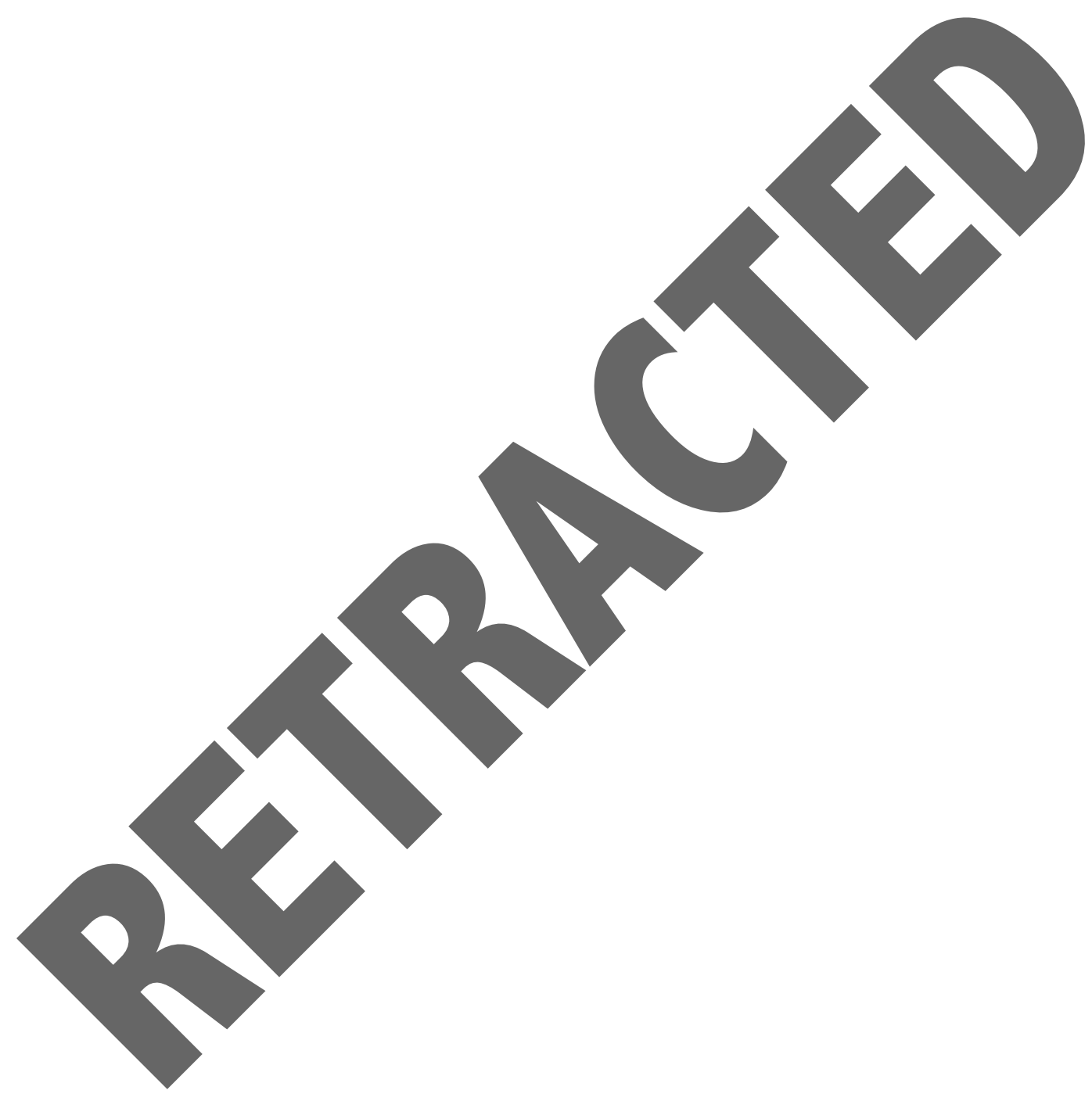

